\title{
VIBRATIONAL ANALYSIS OF GLASS/CARBON FIBER REINFORCED HYBRID LAMINATE COMPOSITES
}

\author{
KAMAL SINGH $^{1}$, NAMAN JAIN ${ }^{2 *}$, JitendRA BHASKAR ${ }^{1}$ \\ ${ }^{1}$ Mechanical Engineering Department, Harcourt Butler Technical University, \\ Kanpur India \\ ${ }^{2}$ Mechanical Engineering Department, Meerut Institute of Engineering and \\ Technology, Meerut, India
}

[Received: 29 August 2019. Accepted: 03 February 2020]

doi: 10.7546/JTAM.50.20.03.04

\begin{abstract}
In present work fabrication of glass/carbon fiber hybrid composite had been done to tailor the properties of such materials to suit specific demand. The characterization of the hybrid composites had been done on the basic of vibrational analysis. Natural frequency, damping ratio, logarithmic response, and flexural stiffness of hybrid composites had been determined through experimental and numerical technique method. ABAQUS software was used to determine the natural frequency of hybrid composite and results obtained were also validated with experimental work. The result indicated that the quantity, stacking sequence and damping ratio of the carbon-glass fiber affected the natural frequency of hybrid composite. The stacking sequence of the carbon layer gave a significant result to the dynamic characteristic of the carbon-glass fiber hybrid composite. Validation of the natural frequency of composite laminates was also done using ABAQUS software. Result shows that hybrid laminate composites, which have higher natural frequency, have higher stiffness and good strength to absorb load. Whereas, composites, which have low natural frequency have low flexural strength but high damping ratio.
\end{abstract}

KEY WORDS: hybrid composite, vibration analysis, natural frequency, damping.

\section{INTRODUCTION}

Now a day's due to high quality and high firmness to weight proportion utilization of composite gain interest. Researchers are gaining interest in composites due to high strength to weight ratio [1-7], biodegrability aspect [7-14] and application to specific area [15]. From past few years, researcher gain interest in hybrid composites in which more than one reinforcement materials are been used to overcome the specific problem of real life. In addition, the properties of hybrid fiber composites can be tailored for specific applications by changing fiber orientation, combination of different fiber,

\footnotetext{
*Corresponding author e-mail: namanjainyati@gmail.com
} 
blending of matrix material, cross-linking of polymer matrix etc. It has been widely demonstrated that the impact fracture toughness of polymer composites with brittle reinforcements, such as carbon or glass fiber, can be improved by mixing with more ductile organic fibers, such as aramid or polyester [16]. Due to superior properties of hybrid composites, they gain interest in different application such as automobile, marine, aviation industries, aerospace, etc. Hybrid composites are now a day's gain interest in the field of dynamic response. Problems like improvement in impact strength and vibration response are gaining interest of researcher and can be overcome by application of hybrid composites. One of the promising strategies to overcome the impact resistance and toughness is application of fiber hybridization [17]. Naik et al. investigated the effect of stacking sequence of glass-carbon/epoxy on impact behaviour and post-impact compressive strength. Result shows that energy absorbed decrease with decrease in carbon fiber content [18]. Hosur et al. improved the lowvelocity impact response of hybrid composites by reinforcing plain woven S2 glass and twill woven carbon-glass fabrics with SC-15 resin. Load carrying capability of fabricated hybrid laminates considerable improvement as compared to carbon/epoxy laminates [19]. For understanding the dynamic behaviour of composite, we need to understand factors which affect the dynamic response. In past, a lot of work has been done on the static properties of hybrid polymer composites. However, the dynamic properties of hybrid polymer composites have not been completely examined for structural engineering applications. Alexander et al. in 2015 [20] determine the natural frequencies of carbon-epoxy and basalt-epoxy experimentally. Results obtained are also compared with theoretical and software based simulation. Cheng et al. [21] performed software based vibration and damping analysis on wind blade made up of glass fiber reinforced composite. Result shows that damping factor does not affect the natural frequency of blade whereas modal loss actor increases with increase in damping factor. Lavateet et al. [22] performed a dynamic response analysis on fiber-reinforced composite beam to determine the longitudinal, transverse and shear modulus. Result shows that with increase in volume fraction of reinforcement material natural frequency of composite increases. Utomo et al. [23] investigated the dynamic characteristics on glass-carbon hybrid composite. With increase in carbon fiber layer the damping ratio and natural frequency decreases whereas by position the carbon layer in the middle of the laminate composite damping ratio increases.

In present investigations dynamic properties epoxy based composites have been improved by fabricating glass-carbon fiber hybrid composite. Natural frequency, damping ratio, and logarithmic response of fabricated hybrid composite have been evaluated experimental. Experimental result obtained also compared with software (ABAQUS) based simulation. Moreover, mathematical model has been developed to evaluate the dynamic response on the hybrid composite and results obtained also 
compared with experimental and software simulation.

\section{MATERIAL}

In this present investigation, unidirectional carbon and glass fiber were used. The fibers were purchased from by Hindoostan Tech, Mumbai, India. Glass fiber have dry fabric thickness of $0.3 \mathrm{~mm}$, tensile strength of $3100 \mathrm{MPa}$, Young's modulus $80 \mathrm{GPa}$ and density $2.62 \mathrm{~g} / \mathrm{cm}^{3}$. Where carbon have dry fabric thickness of $0.43 \mathrm{~mm}$, tensile strength of $4000 \mathrm{MPa}$, Young's modulus $240 \mathrm{GPa}$ and density $1.8 \mathrm{~g} / \mathrm{cm}^{3}$. Matrix material used for fabrication of hybrid composite is epoxy resin SY-12(319) purchased from M/s MODI BOND Ltd Kanpur, India. Hardener SY31 which is white transparent liquid was taken as curing agent and purchased from M/s MODI BOND Limited, Kanpur, India.USB primarily based data acquisition system, laser sensor, power supply unit and trigger unit used for experiential set-up was purchased from SPRANKTRONICS, Bangalore, India. Clamp Block is the steel support, with $230 \mathrm{~mm}$ height, the length is $335 \mathrm{~mm}$ and the breadth $200 \mathrm{~mm}$.

\section{METHOD}

For fabrication of composite epoxy was put in beakers at $110^{\circ} \mathrm{C}$ for $1 \mathrm{hr}$ in electric oven and then the solution was allowed to cool down to $45^{\circ} \mathrm{C}$. After which, hardener was added in the ratio of 10:1 [24]. Hand-layup technique was employed to finally fabricate the composites. Before fabrication unidirectional carbon and glass fiber were cut into specific size and weighted. First some epoxy-hardener solution was applied on polythene sheet over which fiber layer is placed. Then pressed with the help of roller and then again layer of epoxy-hardener layer is applied and again pressed with roller. Same process is employed for all the layers wither carbon or glass. The whole arrangement was kept for 24 hours for hardening and after that sheets of size of $110 \times 20 \mathrm{~cm}^{2}$ were cut and used for testing. Notation of symmetric hybrid laminate composite is done in square bracket in which ply angle of each lamina is separated by slash in subscript represent glass (g) or carbon fiber (c) and subscript after square bracket represent symmetry about mid lamina. Figure 1(A) represents the fabricated specimen used for experiment.

\section{EXPERIMENTAL SET-UP}

Fabricated specimen was clamp on clamp block as a cantilever beam as shown in Fig. 1(B). A laser sensor which measures the displacement of the free end of cantilever beam was placed at $10 \mathrm{~mm}$ distance from free end of beam. Before performing the experiment impulse response software is started in the computer. After that, specimen was hit by impulse hammer at the free end. Motion of free end of beam was been observed by the Laser sensor and recorded in the computer. All the experiment 
was performed at room temperature as per ASTM E 756 standard [25]. Three sample of each composition was taken to perform the vibrational analysis and there are no voids present in samples. Result represent in figure 3, 4 \& 5 represent mean value with standard deviation.
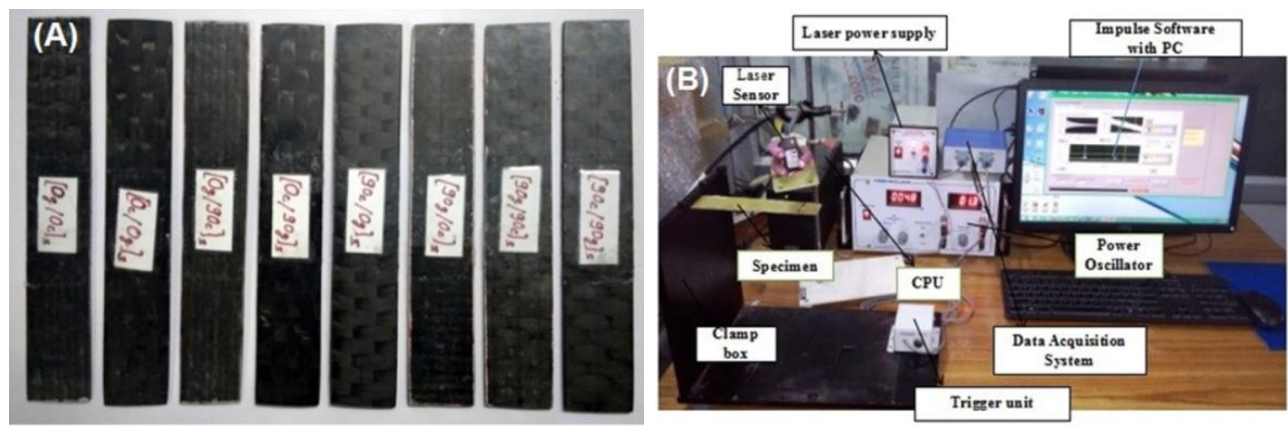

Fig. 1: (A) Fabricated specimen and (B) Experimental set-up.

Flexural stiffness of hybrid laminate composite is calculated by measuring the deflection of free end of the cantilever beam. Free end deflection of cantilever beam is measured with the help of laser sensor and USB based [26] acquisition system Laser sensor is placed 8 to $12 \mathrm{~cm}$ above from the specimen and $1 \mathrm{~cm}$ to far from at the free end. Now applying a certain load of $1.373 \mathrm{~N}$ at the free end for $5 \mathrm{~s}$. After calculating deflection, flexural stiffness calculated with the help of this formula:

$$
\text { flexural stiffness }[\mathrm{N} / \mathrm{mm}]=\frac{\text { Applied load }}{\text { Deflection }} \text {. }
$$

\section{Finite Element AnAlysis}

The characteristics of woven fiber Glass/Epoxy composite plate which can be defined completely by four material constants: $E_{1}, E_{2}, \nu_{12}$ and $G_{12}$ where the suffixes 1 and 2 indicate principal material directions. The values above material constants were determined by rule of mixture [27]

$$
\begin{aligned}
& E_{1}=E_{f} V_{f}+E_{m} V_{m}, \\
& E_{2}=\frac{E_{m} E_{f}}{E_{m} V_{f}+E_{f} V_{m}}, \\
& \nu_{12}=\nu_{f} V_{f}+\nu_{m} V_{m}, \\
& v_{21}=v_{12} \frac{E_{2}}{E_{1}}, \\
& \nu_{23}=1-\nu_{21}-\frac{E_{2}}{3 K},
\end{aligned}
$$


where $K=\left[\frac{V_{f}}{K_{f}}+\frac{V_{m}}{K_{m}}\right]^{-1}, K_{m}=\frac{E_{m}}{3\left(1-2 \nu_{m}\right)}$ and $K_{f}=\frac{E_{f}}{3\left(1-2 \nu_{f}\right)}$

$$
G_{12}=\frac{G_{f} G_{m}}{G_{m} V_{f}+G_{f}\left(1-V_{f}\right)}
$$

where $G_{f}=\frac{E_{f}}{2\left(1-\nu_{f}\right)}$ and $G_{m}=\frac{E_{m}}{2\left(1-\nu_{m}\right)}$,

$$
G_{23}=\frac{E_{2}}{2\left(1+\nu_{23}\right)}
$$

where $V_{f}$ is a volume fraction of fiber; $V_{m}$ is a volume fraction of matrix; $\nu_{f}$ and $\nu_{m}$ are Poison's ratios of fiber and matrix, respectively.

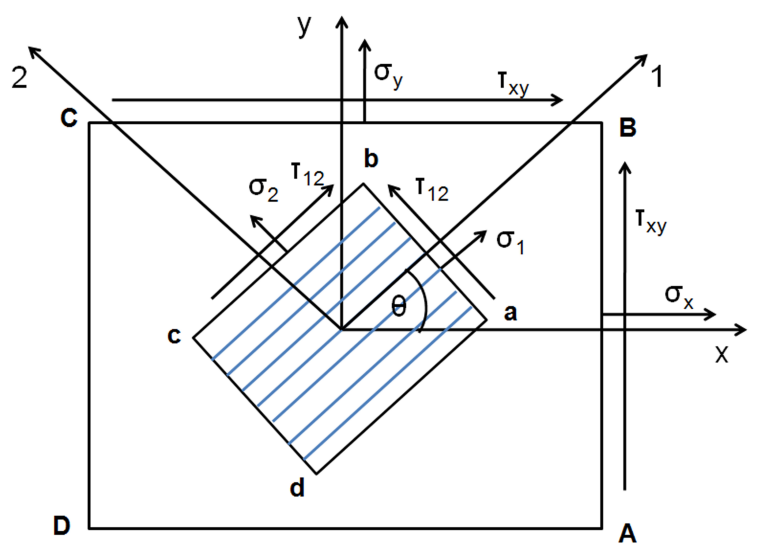

Fig. 2: Lamina at an arbitrary orientation.

Let us consider that fibers are oriented at angle $\theta$ as shown in Fig. 2 with respect to global co-ordinate system (X-Y). And the thickness of lamina is considered to be unity. The stress-strain relation is presented in equation 8 and 9

$$
\{\sigma\}=[Q]\{\varepsilon\},
$$

where $Q$ is the stiffness matrix;

$$
\left\{\begin{array}{c}
\sigma_{1} \\
\sigma_{2} \\
\tau_{12}
\end{array}\right\}=\left[\begin{array}{ccc}
Q_{11} & Q_{12} & 0 \\
Q_{12} & Q_{22} & 0 \\
0 & 0 & Q_{66}
\end{array}\right]\left\{\begin{array}{c}
\epsilon_{1} \\
\epsilon_{2} \\
\gamma_{12}
\end{array}\right\}
$$


w.r.t. local co-ordinate system (1-2), where

$$
\begin{aligned}
Q_{11} & =\frac{E_{L}}{1-v_{L T} v_{T L}}, \\
Q_{22} & =\frac{E_{T}}{1-v_{L T} v_{T L}}, \\
Q_{12} & =\frac{v_{L T} E_{T}}{1-v_{L T} v_{T L}}=\frac{v_{T L} E_{L}}{1-v_{L T} v_{T L}}, \\
Q_{66} & =G_{12} .
\end{aligned}
$$

Stresses in global co-ordinate system can be related with local co-ordinate system by following equations:

$$
\left\{\begin{array}{c}
\sigma_{1} \\
\sigma_{2} \\
\tau_{12}
\end{array}\right\}=[T]\left\{\begin{array}{c}
\sigma_{x} \\
\sigma_{y} \\
\tau_{x y}
\end{array}\right\},
$$

where

$$
\begin{aligned}
& T=\left[\begin{array}{ccc}
\cos \theta^{2} & \sin \theta^{2} & 2 \sin \theta \cos \theta \\
\sin \theta^{2} & \cos \theta^{2} & -2 \sin \theta \cos \theta \\
-\sin \theta \cos \theta & \sin \theta \cos \theta & \cos \theta^{2}-\sin \theta^{2}
\end{array}\right] \text { or } \\
& T=\left[\begin{array}{ccc}
C^{2} & S^{2} & S C \\
S^{2} & C^{2} & -S C \\
-2 S C & 2 S C & C^{2}-S^{2}
\end{array}\right], \\
& \left\{\begin{array}{c}
\sigma_{x} \\
\sigma_{y} \\
\tau_{x y}
\end{array}\right\}=[T]^{-1}\left[\begin{array}{ccc}
Q_{11} & Q_{12} & 0 \\
Q_{12} & Q_{22} & 0 \\
0 & 0 & Q_{66}
\end{array}\right]\left\{\begin{array}{c}
\epsilon_{1} \\
\epsilon_{2} \\
\gamma_{12}
\end{array}\right\}, \\
& \left\{\begin{array}{c}
\sigma_{x} \\
\sigma_{y} \\
\tau_{x y}
\end{array}\right\}=[T]^{-1}\left[\begin{array}{ccc}
Q_{11} & Q_{12} & 0 \\
Q_{12} & Q_{22} & 0 \\
0 & 0 & Q_{66}
\end{array}\right][T]\left\{\begin{array}{c}
\epsilon_{x} \\
\epsilon_{y} \\
\gamma_{x y}
\end{array}\right\} .
\end{aligned}
$$

Similar transformation is been used for strain, therefore stress-strain relation w.r.t. global coordination system is represent by equation

$$
\left\{\begin{array}{c}
\sigma_{x} \\
\sigma_{y} \\
\tau_{x y}
\end{array}\right\}=\left[\begin{array}{lll}
\bar{Q}_{11} & \bar{Q}_{12} & \bar{Q}_{16} \\
\bar{Q}_{12} & \bar{Q}_{22} & \bar{Q}_{26} \\
\bar{Q}_{16} & \bar{Q}_{26} & \bar{Q}_{66}
\end{array}\right]\left\{\begin{array}{c}
\epsilon_{x} \\
\epsilon_{y} \\
\gamma_{x y}
\end{array}\right\},
$$

where $[\bar{Q}]=[T]^{-1}[Q][T]$. 
For macro-mechanical analysis of laminate the preceding strain-displacement relation can be written in terms of the midplane strains and the plate curvatures as follows:

$$
\left\{\begin{array}{c}
\epsilon_{x} \\
\epsilon_{x} \\
\epsilon_{x}
\end{array}\right\}=\left\{\begin{array}{c}
\epsilon_{x}^{0} \\
\epsilon_{y}^{0} \\
\epsilon_{x y}^{0}
\end{array}\right\}+z\left\{\begin{array}{c}
k_{x} \\
k_{y} \\
k_{x y}
\end{array}\right\} .
$$

Resultant force is obtained by integrating the corresponding stress through the laminate thickness $h$

$$
\left\{\begin{array}{c}
N_{x} \\
N_{y} \\
N_{x y}
\end{array}\right\}=\sum_{k=1}^{n} \int_{h_{k-1}}^{h_{k}}\left\{\begin{array}{c}
\sigma_{x} \\
\sigma_{y} \\
\tau_{x y}
\end{array}\right\} d z .
$$

Similarly, the resultant moment is obtained by integration through the thickness of the corresponding stress times the moment arm with respect to the mid-plane

$$
\left\{\begin{array}{c}
M_{x} \\
M_{y} \\
M_{x y}
\end{array}\right\}=\sum_{k=1}^{n} \int_{h_{k-1}}^{h_{k}}\left\{\begin{array}{c}
\sigma_{x} \\
\sigma_{y} \\
\tau_{x y}
\end{array}\right\}_{k} z d z .
$$

Combining equations (19), (20), and (21), we obtain

$$
\begin{aligned}
& \left\{\begin{array}{l}
N \\
M
\end{array}\right\}=\left[\begin{array}{ll}
A & B \\
B & D
\end{array}\right]\left\{\frac{\epsilon^{0}}{k}\right\}, \\
& \left\{\begin{array}{c}
N_{x} \\
N_{y} \\
N_{x y}
\end{array}\right\}=\left[\begin{array}{lll}
A_{11} & A_{12} & A_{16} \\
A_{12} & A_{22} & A_{26} \\
A_{16} & A_{26} & A_{66}
\end{array}\right]\left\{\begin{array}{c}
\epsilon_{x}^{0} \\
\epsilon_{y}^{0} \\
\epsilon_{x y}^{0}
\end{array}\right\}+\left[\begin{array}{lll}
B_{11} & B_{12} & B_{16} \\
B_{12} & B_{22} & B_{26} \\
B_{16} & B_{26} & B_{66}
\end{array}\right]\left\{\begin{array}{c}
k_{x} \\
k_{y} \\
k_{x y}
\end{array}\right\}, \\
& \left\{\begin{array}{c}
M_{x} \\
M_{y} \\
M_{x y}
\end{array}\right\}=\left[\begin{array}{lll}
B_{11} & B_{12} & B_{16} \\
B_{12} & B_{22} & B_{26} \\
B_{16} & B_{26} & B_{66}
\end{array}\right]\left\{\begin{array}{c}
\epsilon_{x}^{0} \\
\epsilon_{y}^{0} \\
\epsilon_{x y}^{0}
\end{array}\right\}+\left[\begin{array}{lll}
D_{11} & D_{12} & D_{16} \\
D_{12} & D_{22} & D_{26} \\
D_{16} & D_{26} & D_{66}
\end{array}\right]\left\{\begin{array}{c}
k_{x} \\
k_{y} \\
k_{x y}
\end{array}\right\},
\end{aligned}
$$

where

$$
\begin{aligned}
A_{i j} & =\sum_{k=1}^{n}\left(\overline{Q_{i j}}\right)_{k}\left(h_{k}-h_{k-1}\right), \\
B_{i j} & =\frac{1}{2} \sum_{k=1}^{n}\left(\overline{Q_{i j}}\right)_{k}\left(h_{k}^{2}-h_{k-1}^{2}\right), \\
C_{i j} & =\frac{1}{3} \sum_{k=1}^{n}\left(\overline{Q_{i j}}\right)_{k}\left(h_{k}^{3}-h_{k-1}^{3}\right) .
\end{aligned}
$$


For orthotropic material above equation satisfy the following conditions:

$$
A_{16}=A_{26}=0, \quad B_{i j}=0, \quad D_{16}=D_{26}=0 .
$$

\section{Free Vibration of CANTILEVER BEAm}

The basic element matrix equation governing the transverse vibration is obtained as follows:

$$
\begin{gathered}
\frac{E I}{\rho A} \frac{\partial^{4} w}{\partial x^{4}}(x t)+\frac{\partial^{2} w}{\partial t^{2}}(x t)=0, \\
E I \frac{\partial^{4} w}{\partial x^{4}}+\rho A \frac{\partial^{2} w}{\partial t^{2}}=0 .
\end{gathered}
$$

Assume a harmonic vibration solution

$$
\begin{gathered}
w(x, t)=w(x) e^{-i \omega t}, \\
\frac{\partial^{4} w}{\partial x^{4}}=\frac{\partial^{4} w}{\partial x^{4}} e^{-i \omega t},
\end{gathered}
$$

and

$$
\frac{\partial^{2} w}{\partial x^{2}}=-w \omega^{2} e^{-i \omega t} .
$$

From above equation we get

$$
E I w+\rho A \omega^{2} w=0 .
$$

Consider the beam is divided into a number of elements. Consider a typical EulerBernoulli beam element

$$
v=N_{1} w_{1}+N_{2} \theta_{1}+N_{3} w_{2}+N_{4} \theta_{2}=\sum_{j=1}^{4} \Delta_{j}^{(e)} N_{j}(x) .
$$

Applying Galerkin method to differential equation yields for an element

$$
\int_{a}^{b} N_{i}\left[E I \frac{\partial^{4} w}{\partial x^{4}}+\rho A \omega^{2} w\right] d x=0 .
$$

Integrating the fourth order derivative by parts twice 


$$
\begin{aligned}
{\left[N_{i} \frac{\partial}{\partial x}\left(E I \frac{\partial^{2} w}{\partial x^{2}}\right)\right]_{a}^{b} } & -\left[\frac{\partial N_{i}}{\partial x}\left(E I \frac{\partial^{2} w}{\partial x^{2}}\right)\right]_{a}^{b} \\
& +\int_{a}^{b} E I \frac{\partial^{2} N_{i}}{\partial x^{2}} \frac{\partial^{2} w}{\partial x^{2}} d x+\int_{a}^{b} N_{i} \rho A \omega^{2} w d x=0 .
\end{aligned}
$$

Above equation can be written in matrix form

$$
\begin{aligned}
& \left([K]^{e}-\omega^{2}[M]^{e}\right)[\Delta]^{e}=\{Q\}^{e}, \\
& k_{i j}^{e}=\int_{a}^{b} E I \frac{\partial^{2} N_{i}}{\partial x^{2}} \frac{\partial^{2} N_{j}}{\partial x^{2}} d x, \\
& m_{i j}^{e}=\int_{a}^{b} \rho A N_{i} N_{j} d x .
\end{aligned}
$$

where

$$
\begin{aligned}
Q_{1} & =\left.\left[\frac{\partial}{\partial x}\left(E I \frac{\partial^{2} w}{\partial x^{2}}\right)\right]\right|_{a}, & Q_{2} & =\left.\left(E I \frac{\partial^{2} w}{\partial x^{2}}\right)\right|_{a} \\
Q_{3} & =-\left.\left[\frac{\partial}{\partial x}\left(E I \frac{\partial^{2} w}{\partial x^{2}}\right)\right]\right|_{b}, & Q_{4} & =-\left.\left(E I \frac{\partial^{2} w}{\partial x^{2}}\right)\right|_{b} .
\end{aligned}
$$

Now element and mass matrices can be evaluated using interpolation function derived for $C^{1}$ continuity. Interpolation functions are

$$
\begin{gathered}
N_{1}=1-\frac{3}{L^{2}} x^{2}+\frac{2}{L^{3}} x^{3}, \\
N_{2}=-x+\frac{2}{L} x^{2}-\frac{1}{L^{2}} x^{3} \\
N_{3}=-\frac{3}{L^{2}} x^{2}-\frac{2}{L^{3}} x^{3}, \\
N_{4}=\frac{1}{L} x^{2}-\frac{1}{L^{2}} x^{3}, \\
k_{11}=\int_{0}^{h} E I \frac{\partial^{2} N_{1}}{\partial x^{2}} \frac{\partial^{2} N_{1}}{\partial x^{2}} d x=\frac{12 E I}{L^{3}}, \\
k_{12}=\int_{0}^{h} E I \frac{\partial^{2} N_{1}}{\partial x^{2}} \frac{\partial^{2} N_{2}}{\partial x^{2}} d x=\frac{-6 E I}{L^{2}} .
\end{gathered}
$$


Similarly other coefficient can be obtained

$$
[k]^{e}=\frac{2 E I}{L^{3}}\left[\begin{array}{cccc}
6 & -3 L & -6 & -3 L \\
-3 L & 2 L^{2} & 3 L & L^{2} \\
-6 & 3 L & 6 & 3 L \\
-3 L & L^{2} & 3 L & 2 L^{2}
\end{array}\right]
$$

Now mass matrix is evaluated

$$
\begin{gathered}
{[m]^{e}=\int_{0}^{h} \rho A N_{i} N_{j} d x} \\
\int_{0}^{h}\left(1-\frac{3 x}{L^{2}}+\frac{2 x^{3}}{L^{3}}\right)^{2} d x=\frac{156 L \rho A}{420} .
\end{gathered}
$$

Similarly other coefficient can be found

$$
[m]^{e}=\frac{\rho^{e} A^{e} L^{e}}{420}\left[\begin{array}{cccc}
156 & -22 L & 54 & 13 L \\
-22 L & 4 L^{2} & -13 L & -3 L^{2} \\
54 & -13 L & 156 & 22 L \\
13 L & -3 L^{2} & 22 L & 4 L^{2}
\end{array}\right]
$$

Now governing equation is written as

(44) $\left\{\frac{2 E I}{L^{3}}\left[\begin{array}{cccc}6 & -3 L & -6 & -3 L \\ -3 L & 2 L^{2} & 3 L & L^{2} \\ -6 & 3 L & 6 & 3 L \\ -3 L & L^{2} & 3 L & 2 L^{2}\end{array}\right]\right.$

$$
\left.-\omega^{2} \frac{\rho A L}{420}\left[\begin{array}{cccc}
156 & -22 L & 54 & 13 L \\
-22 L & 4 L^{2} & -13 L & -3 L^{2} \\
54 & -13 L & 156 & 22 L \\
13 L & -3 L^{2} & 22 L & 4 L^{2}
\end{array}\right]\right\}\{q\}=0
$$

where $\omega$ is natural frequency of free vibration of cantilever beam. Similarly we can evaluate natural frequency for especially orthotropic laminate 
(45)

$$
\begin{gathered}
\left\{\frac{2 b D_{11}}{L^{3}}\left[\begin{array}{cccc}
6 & -3 L & -6 & -3 L \\
-3 L & 2 L^{2} & 3 L & L^{2} \\
-6 & 3 L & 6 & 3 L \\
-3 L & L^{2} & 3 L & 2 L^{2}
\end{array}\right]\right. \\
\left.-\omega^{2} \frac{\rho A L}{420}\left[\begin{array}{cccc}
156 & -22 L & 54 & 13 L \\
-22 L & 4 L^{2} & -13 L & -3 L^{2} \\
54 & -13 L & 156 & 22 L \\
13 L & -3 L^{2} & 22 L & 4 L^{2}
\end{array}\right]\right\}\{q\}=0 \\
\omega=\beta^{2} \sqrt{\frac{E I}{\rho A}}=(\beta l)^{2} \sqrt{\frac{E I}{\rho A L^{4}}}
\end{gathered}
$$

$\omega$ is called the natural frequency of vibration. The common boundary conditions are as follows:

1. Beam fixed at one end and free at the other: $\beta_{n} L=(2 n-1) \frac{\pi}{2}$;

2. Beam simply supported at both ends: $\beta_{n} L=n \pi$;

3. Beam fixed at both ends: $\beta_{n} L=(2 n+1) \frac{\pi}{2}$.

\section{Free VibRations for LAMINATED BEAM}

The equation of motion for laminated beams can be derived in a similar manner to the equation of motion for plates

$$
b D_{11} \frac{d^{4} W_{0}}{d x^{4}}+\rho A \frac{d^{2} W_{0}}{d t^{2}}=0,
$$

where $\rho$ is mass per unit volume and $A$ is cross sectional area of the beam.

The solution is

$$
W_{0}(x, t)=W(x) e^{i \omega t},
$$

where $\omega$ is the frequency of vibration

$$
\begin{gathered}
b D_{11} \frac{d^{4} W}{d x^{4}}-\rho A \omega^{2} W=0, \\
W(x)=\sum_{m=1}^{\infty} W_{m} \sin \left(\frac{m \pi x}{L}\right) .
\end{gathered}
$$


Put eq. (49) into (48)

$$
\omega_{m}=\frac{m^{2}\left(\beta_{n} L\right)^{2}}{L^{2}} \sqrt{\frac{b D_{11}}{\rho A}} .
$$

A natural frequency can be determined for any value of $m$ from eq. (50) and the corresponding mode shape from eq. (49). The fundamental frequency that is lowest natural frequency occurs when $m=1$

$$
\omega_{1}=\frac{(\beta L)^{2}}{L^{2}} \sqrt{\frac{b D_{11}}{\rho A}} .
$$

Mode shape

$$
W(x)=\sin \left(\frac{\pi x}{L}\right) .
$$

\section{RESUlTS AND DisCUSSIONS}

Effect of stacking sequence and orientation angle on dynamic response of hybrid laminate composite are shown in Fig. 3. Figure 4 represents variation of natural frequency when orientation angle and stacking sequence of carbon and glass fiber lamina is changed. Result shows that when glass fiber lamina at both ply angle, i.e. $0^{\circ}$ and $90^{\circ}$ comes to center most position improved the natural frequency of hybrid laminate composites. When outermost fiber orientation is zero as compared between $\left[0_{\mathrm{g}} / 0_{\mathrm{c}}\right]_{\mathrm{S}} /\left[0_{\mathrm{c}} / 0_{\mathrm{g}}\right]_{\mathrm{s}}$ and $\left[0_{\mathrm{g}} / 90_{\mathrm{c}}\right]_{\mathrm{s}} /\left[0_{\mathrm{c}} / 90_{\mathrm{g}}\right]_{\mathrm{s}}$ hybrid composite. Whereas, when outermost fiber orientation is 90 as compared between $\left[90_{\mathrm{c}} / 0_{\mathrm{g}}\right]_{\mathrm{S}} /\left[90_{\mathrm{g}} / 0_{\mathrm{c}}\right]_{\mathrm{s}}$ and $\left[90_{\mathrm{g}} / 90_{\mathrm{c}}\right]_{\mathrm{s}} /\left[90_{\mathrm{c}} / 90_{\mathrm{g}}\right]_{\mathrm{S}}$ hybrid composite. Then carbon fiber lamina at both ply angle, i.e. $0^{\circ}$ and $90^{\circ}$ comes to center most position improved the natural frequency. Highest natural frequency is obtained by $\left[0_{\mathrm{c}} / 90_{\mathrm{g}}\right]_{\mathrm{S}}$ hybrid composite while lowest by $\left[90_{\mathrm{c}} / 0_{\mathrm{g}}\right]_{\mathrm{S}}$ hybrid composite. No such pattern is been observed in case of damping ratio. Figure 5 represents the variation of damping ratio with respect to orientation angle and stacking sequence. Highest damping ratio is obtained by $\left[90_{\mathrm{c}} / 90_{\mathrm{g}}\right]_{\mathrm{S}}$ hybrid composite while lowest by $\left[0_{\mathrm{g}} / 0_{\mathrm{c}}\right]_{\mathrm{s}}$ hybrid composite.

Damping ratio is a parameter defines that how rapidly the amplitude of vibration system decays with respect to time. If damping ratio less than 1 then system is called under damped. If the ratio is 0 that means there is no damping present, it means no energy is lost and system will oscillate forever. Overall large damping ratio means energy is decaying rapidly can be say material is weak in strength. In above samples, $\left[90_{\mathrm{g}} / 90_{\mathrm{c}}\right]_{\mathrm{s}},\left[90_{\mathrm{c}} / 90_{\mathrm{g}}\right]_{\mathrm{s}}$ both have higher damping ratio and $\left[0_{\mathrm{c}} / 0_{\mathrm{g}}\right]_{\mathrm{s}}$ has higher natural frequency and lower damping ratio. 


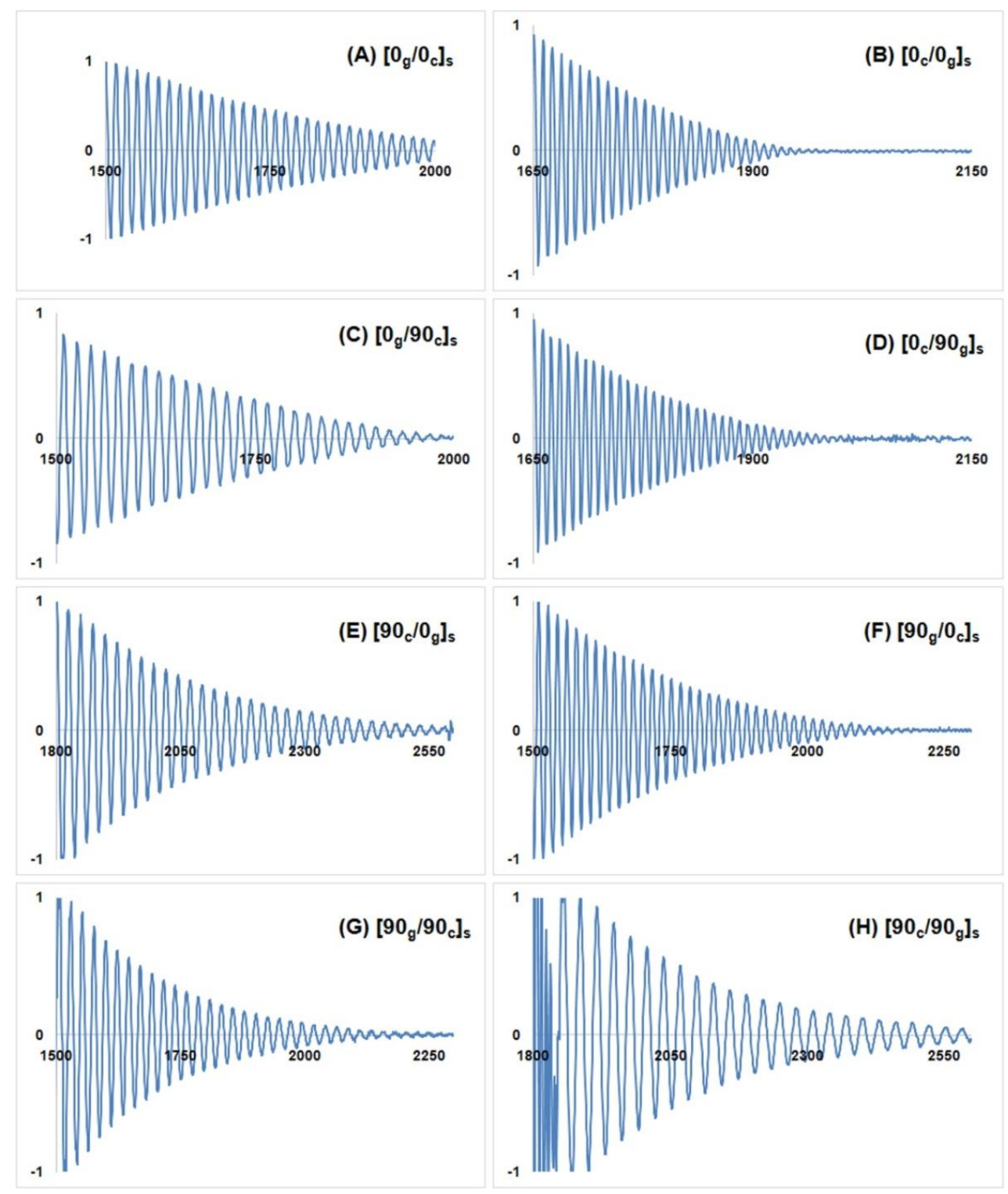

Fig. 3: Dynamic response of hybrid composites.

Figure 6 represents the variation of flexural stiffness of laminate composites at different fiber orientation and stacking sequence. Similar observation is been seen as in case of natural frequency. It shows the hybrid laminate composites, which have 


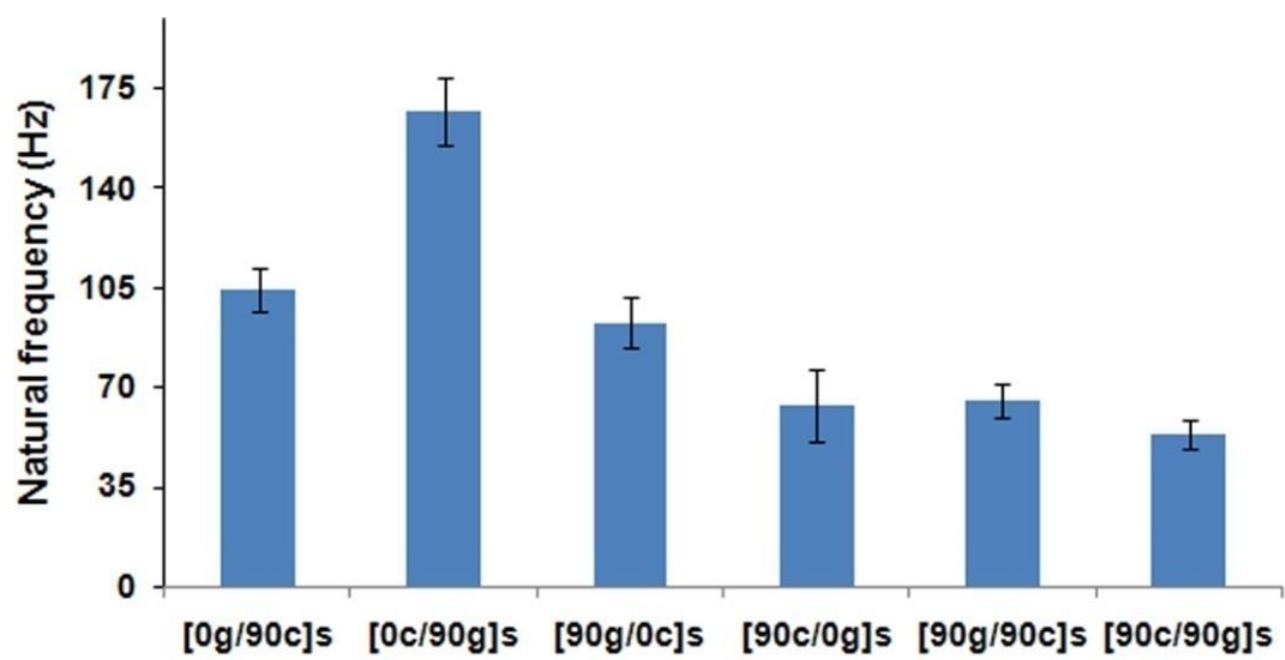

Fig. 4: Natural frequency of hybrid composites.

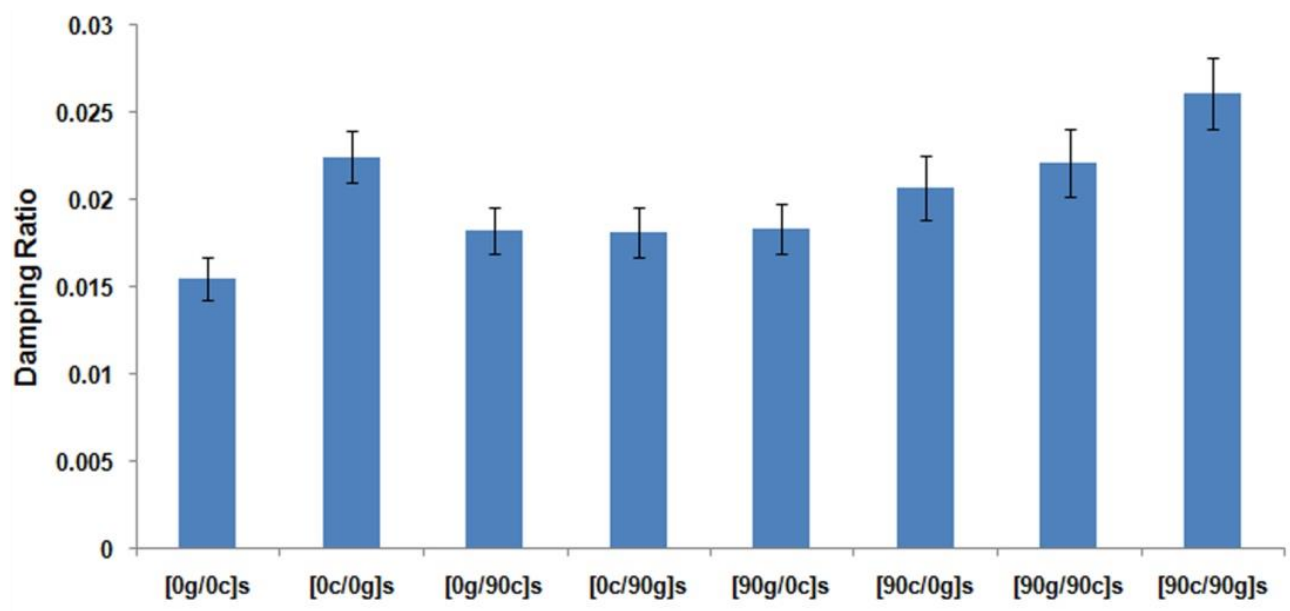

Fig. 5: Damping factor of hybrid composites.

higher natural frequency had higher stiffness and good strength to absorb load. That is, if natural frequency is relatively low, then the material has low flexural strength, but vibration absorption quality is good. Composites, which have low natural frequency and flexural strength, have higher values of damping ration. It means a lower stiffness composite has good vibration absorber. 


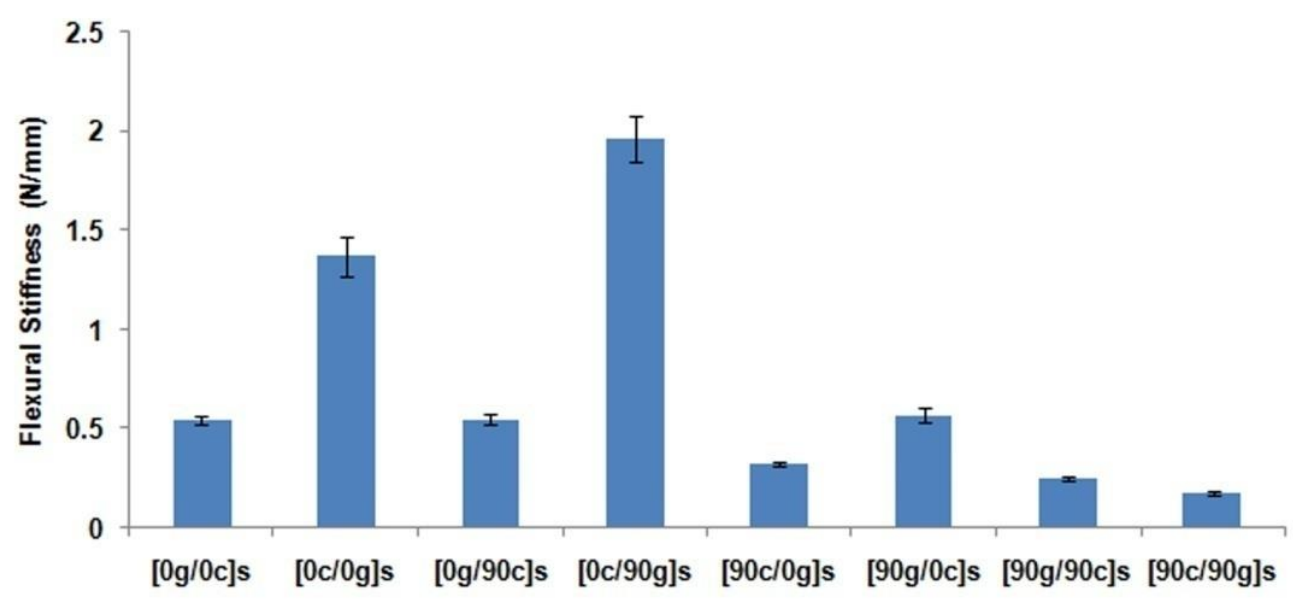

Fig. 6: Flexural stiffness of hybrid composites.

\section{COMPARISON OF THE EXPERIMENTAL DATA WITH OTHER NUMERICAL DATA}

In this research work, software based simulation is also done and result obtained were also compared. Main purpose of the software simulation to provide mathematical model for vibration analysis problem of hybrid laminate composite. Before performing the analysis physical properties such as density, volume, weight etc as shown in Table 1 . Sample size was taken as $100 \times 200 \times 1.45$ for all eight laminate composites. Laminate composite is orthotropic in nature therefore; value of $E_{1}, E_{2}$, $v_{12}, G_{12}, G_{13}$ and $G_{23}$ were been calculated by rule of mixture and also presented in Table 1.

The result obtained from the analysis is compared with available results of references. Natural frequencies obtained from experimental and ABAQUS are listed in tables and those results comparing with the available results of references for the composite laminated beam with fixed-free boundary conditions. And mode shapes are presented by graphs for different boundary conditions. To find out the natural frequencies and mode shapes of beam, finite element solution program done by ABAQUS, Vibration analysis studies of hybrid polymer composite beam Length $(L)$ $=100 \mathrm{~mm}$, Breadth $(b)=20 \mathrm{~mm}$. Maximum deviation of ABAQUS result from the experimental data is about $19 \%$ while for MATLAB is about $16 \%$. Therefore MATLAB based mathematical model provide better result as compared to ABAQUS software. 
Table 1: Physical properties of samples

\begin{tabular}{cccccc}
\hline \hline S.No. & Samples & Weight $($ grams $)$ & Thickness $(\mathrm{mm})$ & Volume $\left(\mathrm{cm}^{3}\right)$ & Density $\left(\mathrm{g} / \mathrm{cm}^{3}\right)$ \\
\hline 1 & {$\left[0_{\mathrm{g}} / 0_{\mathrm{c}}\right]_{\mathrm{s}}$} & 4.896 & 1.25 & 2.750 & 1.7803 \\
2 & {$\left[0_{\mathrm{c}} / 0_{\mathrm{g}}\right]_{\mathrm{s}}$} & 5.624 & 1.40 & 3.080 & 1.8259 \\
3 & {$\left[0_{\mathrm{g}} / 90_{\mathrm{c}}\right]_{\mathrm{s}}$} & 5.647 & 1.45 & 3.190 & 1.7702 \\
4 & {$\left[0_{\mathrm{c}} / 90_{\mathrm{g}}\right]_{\mathrm{s}}$} & 7.010 & 1.50 & 3.300 & 2.1240 \\
5 & {$\left[90_{\mathrm{c}} / 0_{\mathrm{g}}\right]_{\mathrm{s}}$} & 7.189 & 1.75 & 3.850 & 1.8672 \\
6 & {$\left[90_{\mathrm{g}} / 0_{\mathrm{c}}\right]_{\mathrm{s}}$} & 6.331 & 1.70 & 3.740 & 1.6927 \\
7 & {$\left[90_{\mathrm{g}} / 90_{\mathrm{c}}\right]_{\mathrm{s}}$} & 5.840 & 1.50 & 3.300 & 1.769 \\
8 & {$\left[90_{\mathrm{c}} / 90_{\mathrm{g}}\right]_{\mathrm{s}}$} & 5.926 & 1.50 & 3.300 & 1.795 \\
\hline \multicolumn{5}{r}{} \\
\hline
\end{tabular}

\begin{tabular}{lccccccc}
\hline Lamina & $E_{1}$ & $E_{2}$ & $\nu_{12}$ & Density & $G_{12}$ & $G_{13}$ & $G_{23}$ \\
\hline
\end{tabular}

Glass/epoxy $34.62 \mathrm{GPa} 5.72 \mathrm{GPa} 0.2851 .985 \mathrm{~g} / \mathrm{cm}^{3} 2.158 \mathrm{GPa} 2.158 \mathrm{GPa} 1.783 \mathrm{GPa}$

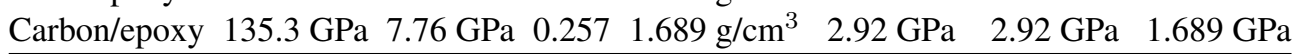

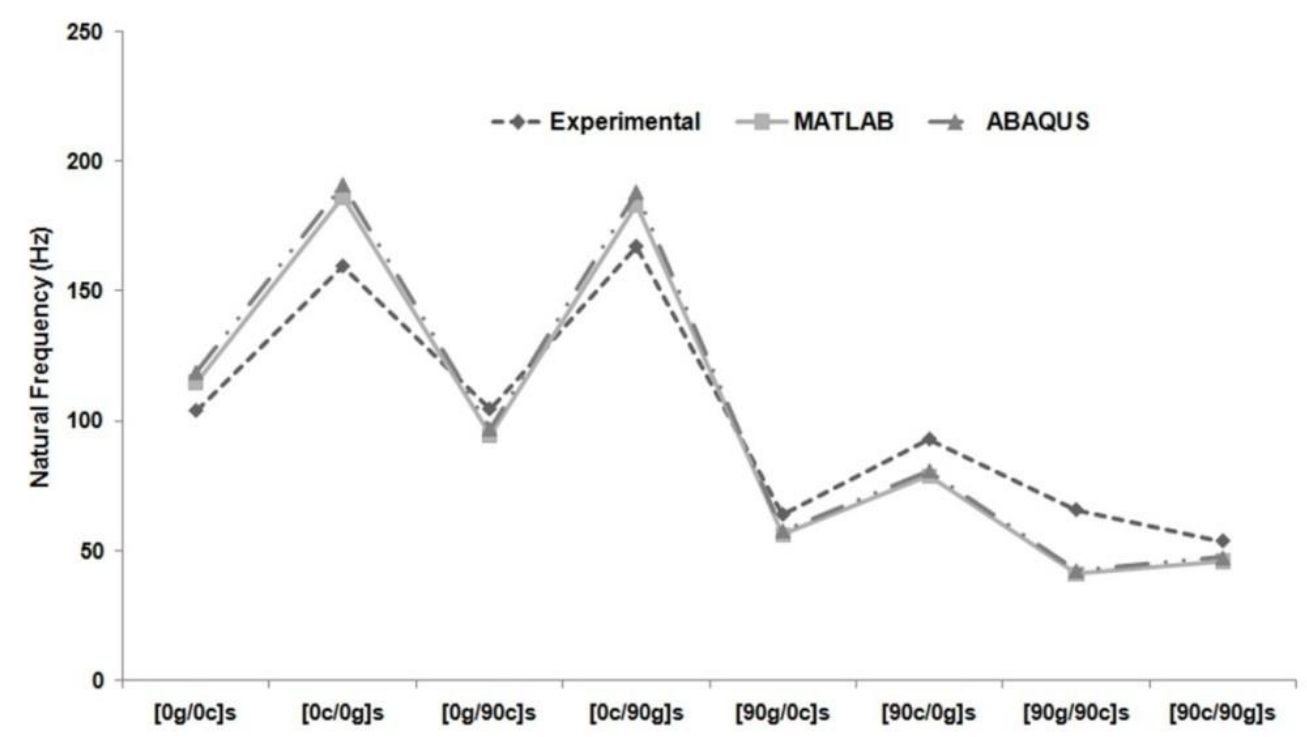

Fig. 7: Comparison of natural frequencies via Experimental method, Analytical method and ABAQUS.

\section{CONCLUSIONS}

The following conclusions can be made from the present investigations of the rectangular plate hybrid polymer composite of glass fiber/carbon fiber/epoxy: 
1. Laminates $\left[0_{\mathrm{c}} / 90_{\mathrm{g}}\right]_{\mathrm{s}}$ has highest flexural stiffness and laminates $\left[90_{\mathrm{c}} / 90_{\mathrm{g}}\right]_{\mathrm{s}}$ have lowest natural frequency and lowest flexural stiffness.

2. Composite with low damping ratio has high natural frequency and low deflection.

3. Unidirectional carbon fiber composites are stiffer than glass fiber composites because elastic modulus of carbon fiber is higher than glass fiber.

4. The natural frequencies of Hybrid polymer composites are found be higher in which carbon layers were outer sided.

5. There is a good agreement between the experimental and numerical results. MATLAB based results are more in close proximity to experimental results as compared with ABAQUS software.

\section{REFERENCES}

[1] A. Verma, V.K. Singh (2019) Mechanical, Microstructural and Thermal Characterization of Epoxy-Based Human Hair-Reinforced Composites. Journal of Testing and Evaluation 47(2) 1193-1215.

[2] N. Jain, V.K. Singh, S. Chauhan (2017) Review on effect of chemical, thermal, additive treatment on mechanical properties of basalt fiber and their composites. Journal of Mechanical Behavior of Materials 26(5-6) 205-211. DOI: 10.1515/jmbm-2017-0026.

[3] A. Verma, B. Negi, V.K. Singh (2018) Experimental Analysis on Carbon Residuum Transformed Epoxy Resin: Chicken Feather Fiber Hybrid Composite. Polymer Composites 40(7) 2690-2699. DOI: https://doi.org/10.1002/pc.25067.

[4] A. Verma, B. Negi, V.K. Singh (2018) Physical and Thermal Characterization of Chicken Feather Fiber and Crumb Rubber Reformed Epoxy Resin Hybrid Composite. Advances in Civil Engineering Materials 7(1) 538-557.

[5] A. Verma, B. Negi, V.K. Singh (2018) Experimental investigation of chicken feather fiber and crumb rubber reformed epoxy resin hybrid composite: Mechanical and Microstructural characterization. Journal of the Mechanical Behavior of Materials 27(3-4) 1-24.

[6] A. Verma, K. Joshi, A. Gour, V.K. Singh (2017) Mechanical Properties and Microstructure of Starch and Sisal Fiber Biocomposite Modified with Epoxy Resin. Materials Performance and Characterization 6(1) 500-520.

[7] A. Verma, C. Singh, V.K. Singh, N. Jain (2019) Fabrication and Characterization of Chitosan coated Sisal Fiber - Phytagel modified Soy Protein based Green Composite. Journal of Composite Materials 53(18) 2481-2504.

[8] N. Jain, A. Verma, V.K. Singh (2019) Dynamic mechanical analysis and creeprecovery behaviour of polyvinyl alcohol based cross-linked biocomposite reinforced with basalt fiber. Materials Research Express 6(10) 105373, 1-14. 
[9] N. Jain, S. Ali, V.K. Singh, K. Singh, Nitesh, S. Chohan (2019) Creep and Dynamic Mechanical behaviour of Cross-linked polyvinyl alcohol reinforced with cotton fiber laminate composites. Journal of Polymer Engineering 39(4) 326-335. DOI: 10.1515/polyeng-2018-0286.

[10] N. Jain, V.K. Singh, S. Chauhan (2019) Dynamic and Creep-recovery Analysis of Polyvinyl Alcohol Based Cross-linked Composite Reinforced with Basalt Fiber. Materials Research Express 6 105373. DOI: 10.1088/2053-1591/ab4332.

[11] N. JaIn, V.K. Singh, S. Chauhan (2018) Dynamic and Creep Analysis of Polyvinyl Alcohol Based Films Blended with Starch and Protein. Journal of Polymer Engineering 39(1) 26-35. DOI: 10.1515/polyeng-2018-0032.

[12] K. Deepmala, N. Jain, V.K. Singh, S. Chauhan (2018) Fabrication and characterization of chitosan coated human hair reinforced phytagel modified soy proteinbased green composite. Journal of Mechanical Behavior of Materials 27(1-2). DOI: 10.1515/jmbm-2018-0007.

[13] N. Jain, V.K. Singh, S. Chauhan (2017) A review on mechanical and water absorption properties of polyvinyl alcohol based composites/films. Journal of Mechanical Behavior of Materials 26(5-6) 213-222.

[14] A. Verma, K. Joshi, A. Gour, V.K. Singh (2018) Starch-Jute fiber hybrid biocomposite modified with Epoxy resin coating: Fabrication and Experimental Characterization. Journal of the Mechanical Behavior of Materials 27(5-6) 1-16.

[15] A. Verma, A. Parashar, M. Packirisamy (2018) Effect of grain boundaries on the interfacial behaviour of graphene-polyethylene nanocomposite. Applied Surface Science 470 1085-1092.

[16] T.J. Anderson, A.H. J. NAYFeH (2003) Vibration \& Control 2 381-414.

[17] F. SARASINI (2017) Low-velocity impact behaviour of hybrid composites. In: Vijay Kumar Thakur Manju Kumari Thakur Asokan Pappu (eds) "Hybrid Polymer Composite Materials: Properties and Characterisation”. Elsevier Ltd. pp. 151-168. DOI: http://dx.doi.org/10.1016/B978-0-08-100787-7.00007-X

[18] N.K. NAIK, R. RAMASIMH, H. ARYA (2001) Impact response and damage tolerance characteristics of glass-carbon/epoxy hybrid composite plates. Composites Part B: Engineering. 32 565-574.

[19] M.V. Hosur, U.K. Vaidya, C. Ulven (2004) Performance of stitched/ unstitched woven carbon/epoxy composites under high velocity impact loading. Composite Structures 64 455-466.

[20] J. Alexander, H.A. Kumar, B.S.M Augustine (2015) Frequency Response of Composite Laminates at Various Boundary Conditions. International Journal of Engineering Science Invention 11-15.

[21] T.H. Cheng, M. Ren, Z.Z. Li, Y.D. Shen (2015) Vibration and Damping Analysis of Composite Fiber Reinforced Wind Blade with Viscoelastic Damping Control. Advances in Materials Science and Engineering 2015 Article ID 146949. 
[22] R.S. Lavate, A.T. Patil, A.M. Patil, N.V. Hargude (2013) Dynamic Response Analysis of Fiber Reinforced Composite Beam. IOSR Journal of Mechanical and Civil Engineering 6 38-47.

[23] J.T. Utomo, D.D. Susilo, W.W. Raharjo (2017) The influence of the number and position of the carbon fiber lamina on the natural frequency and damping ratio of the carbon-glass hybrid composite. AIP Conference Proceedings 1788030046 DOI: 10.1063/1.4968299.

[24] C. Panneerselvam, M.G. Krishnan, S.G. Babu (2015) Evaluation of Energy Release Rate of Particle Filled GFRP Composite Laminates. International Research Journal of Engineering and Technology 2(9) 2582-2587.

[25] ASTM E756-98 (1998) "Standard test method for measuring vibration-damping properties of materials". American Society for Testing and Materials.

[26] Ö.Y. Bozkurt, M. Bulut, Ö. Özbek (2016). Effect of Fibre Orientations on Damping and Vibration Characteristics of Basalt Epoxy Composite Laminates. In: ICSENM 115-1. DOI: 10.11159/icsenm16.115.

[27] D.A. Bhagwan, J.B Lawrence, K. Chandrashekhara (2006) "Analysis and Performance of Fiber Composites". Wiley. 